\title{
Biological monitoring of exposure to nerve agents
}

\author{
J Bajgar
}

Abstract

Changes in acetylcholinesterase activity in blood and some organs of rats after intoxication with sarin, soman, VX, and 2-dimethylaminoethyl-(dimethylamido)-phosphonofluoridate (GV), in doses of roughly $2 \times \mathbf{L D}_{50}$ given intramuscularly, were obtained from published data and by experiment. The time course of inhibition of acetylcholinesterase in blood, regions of brain, and diaphragm and the occurrence of signs and symptoms of poisoning (none, salivation, disturbed ventilation and fasciculations, convulsions, or death) were summarised and compared. When blood enzyme activities were $70-100 \%$ normal, no obvious signs were seen; at $60-70 \%$, salivation

Military Medical Academy, 50260 Hradec Králové, Czechoslovakia

J Bajgar occurred; at less than $30-55 \%$, disturbed ventilation and fasciculations were seen, and at $15-30 \%$, convulsions occurred. Less than $10 \%$ was fatal. In experiments with narcotised dogs, the blood acetylcholinesterase activity and the ability to reactivate it with trimedoxime were determined after intoxication by intramuscular administration of the four compounds. It is concluded that acetylcholinesterase activity in the blood corresponds to that in the target organs and can be considered as an appropriate parameter for biological monitoring of exposure to nerve gases. Moreover, determination of reactivation of blood acetylcholinesterase gives more information than simple determination of enzyme activity.

Nerve agents are compounds of high toxicity, ${ }^{1}$ one of the many reasons for their possible use as chemical weapons. $^{2}$ Others from this class of chemicals

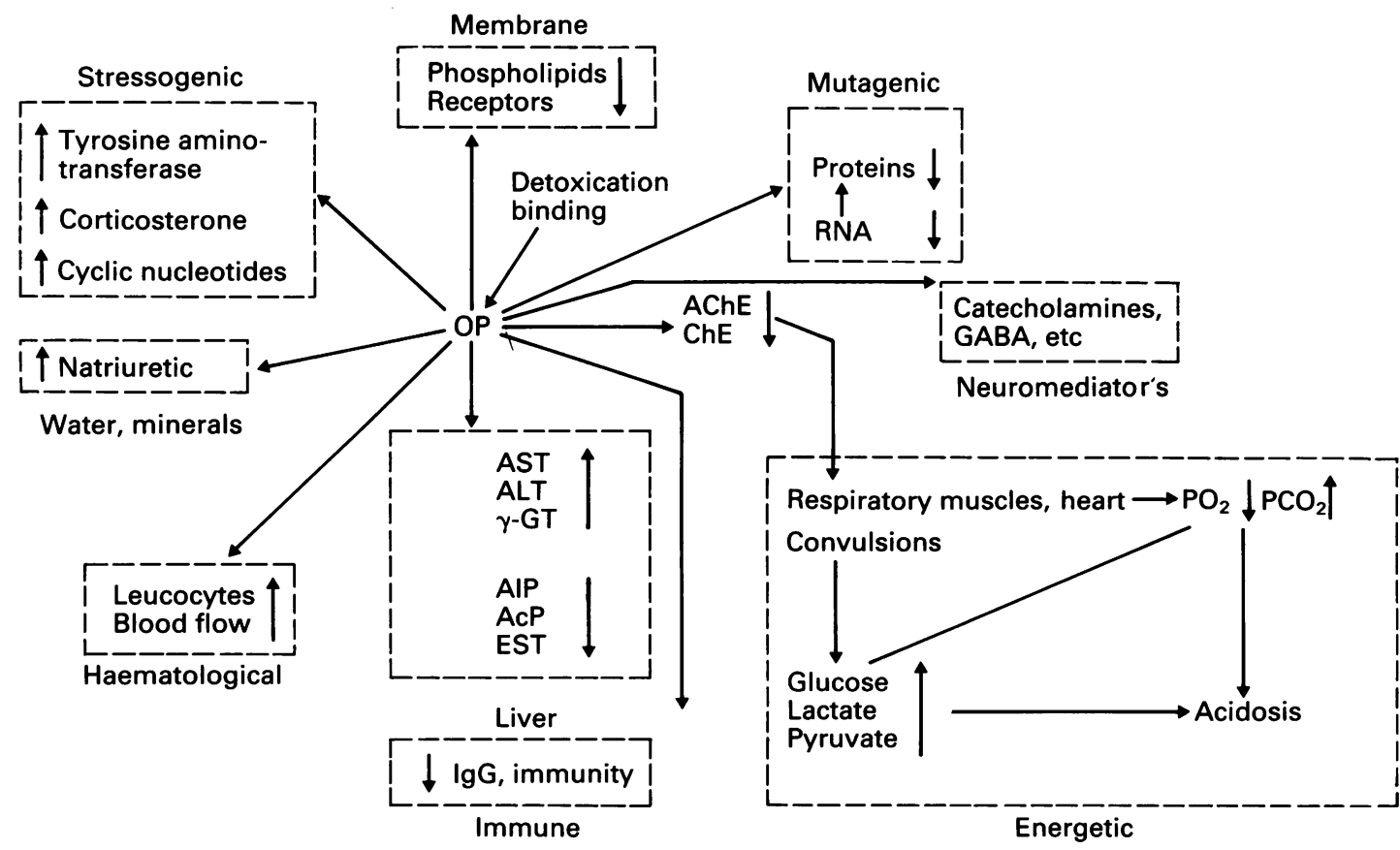

Figure 1 Schematic representation of possible complex effects of organophosphate (OP) action. AST, ALT, AcP, AIP, $E S T, \gamma-G T$ represent transaminases, phosphatases, esterases, and $\gamma$-glutamyltransferase (modified from Bajgar ${ }^{4}$ ). 


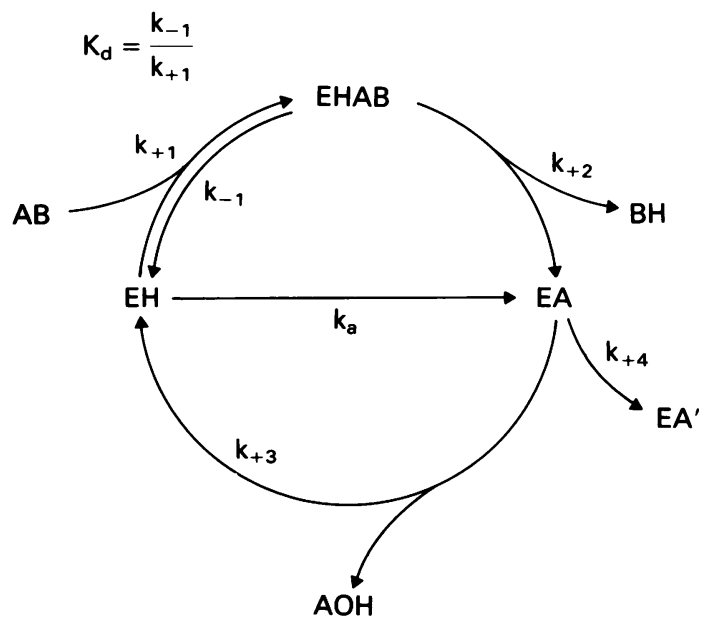

Figure 2 Schematic representation of reaction of organophosphate inhibitor $(A B)$ with leaving group $(B)$ and $A C h E$ ( $E H)$. EHAB, intermediate complex; $E A$, phosphorylated enzyme; $E A^{\prime}$, dealkylated enzyme; $K_{d}$, dissociation constant, $k_{a}$, bimolecular rate constant; $k_{-1}, k_{+1}$, $k_{+2}, k_{+3}$, and $k_{+4}$, rate constants (according to Aldridge $e^{11}$ and Aldridge and Reiner ${ }^{12}$ ).

(organophosphorus compounds) with similar mechanisms of action-but less toxicity-are frequently used as insecticides and medical drugs and they are evaluated by industry. Some of the results and conclusions from this paper could therefore be applied not only to nerve agents but to organophosphates in general.

The basic mechanisms of action of organophosphates (including nerve agents) are well known ${ }^{13}$; they involve cholinesterase inhibition with subsequent accumulation of the neurotransmitter, acetylcholine, changes in membrane permeability, and other metabolic imbalances. Figure 1 shows that these changes are complex. ${ }^{4}$ Attempts to correlate action of nerve agents with changes in blood flow, ${ }^{56}$ detoxication, ${ }^{7}$ and carboxylesterase activity ${ }^{89}$ have been made. Cholinesterase activities in the blood (erythrocyte acetylcholinesterase (AChE, EC 3.1.1.7) and plasma butyrylcholinesterase (BuChE, EC 3.1.1.8)) are the most accessible for monitoring the biological effects of nerve agents. The physiological importance of $\mathrm{AChE}$ is greater than that of BuChE. ${ }^{10}$

The reaction of organophosphates with cholinesterases has been described (fig 2). ${ }^{11}{ }^{12}$ It appears that the principal action (in vitro and in vivo) of organophosphates is inhibition of cholinesterases (especially AChE)..The site of the inhibition depends on the type of agent examined.

We have used previously published data describing symptoms of poisoning and $\mathrm{AChE}$ activity in blood after intoxication with three nerve agents- namely, sarin, soman, and VX. We have also included another anticholinesterase inhibiting substance, 2-dimethylaminoethyl-(dimethylamido)phosphonofluoridate (GV), with a similar toxicity. Figure 3 gives the formulae of the agents used. The questions arise as to whether and where the degree of AChE activity reflects the actual state of the organism or the degree of poisoning and whether $\mathrm{AChE}$ activity in blood is comparable with that in the target organs.

Determination of simple $\mathrm{AChE}$ or BuChE activity (or inhibition) is only one indicator for the biological monitoring of organophosphate action. ${ }^{13}$ For further information on the poisoned organism and especially for its treatment, it is of interest to know if the enzyme inhibition by organophosphate can be reversed (the enzyme can be reactivated). In some cases, depending on the type of organophosphate and on the duration of its action, the inhibited enzyme is changed into a complex that cannot be reactivated. ${ }^{12}$ This has been described as "aging". ${ }^{14}$ The rate of this aging reaction is fast for soman (minutes); AChE activity inhibited by sarin is aged within hours, and aging of $\mathrm{AChE}$ inhibited by VX was not found. ${ }^{14-16}$

No information exists on reactivation of $\mathrm{AChE}$ inhibited by GV. Determination of ability to reactivate inhibited $\mathrm{AChE}$ offers another possibility for the biological monitoring of exposure to organophosphates.

\section{Material and methods}

\section{EVALUATION OF PUBLISHED DATA}

We used published data ${ }^{15-19}$ summarised in the paper by Bajgar ${ }^{20}$ describing the inhibition of $\mathrm{AChE}$ in the blood and other organs of female rats after intra-

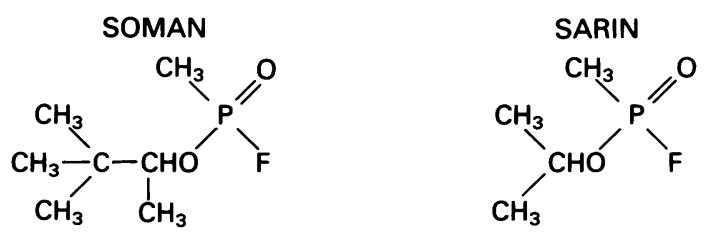<smiles>CCOP(C)(=O)SCCN1C2COC2C2COC21</smiles>

Figure 3 Structural formulae of the agents used. 

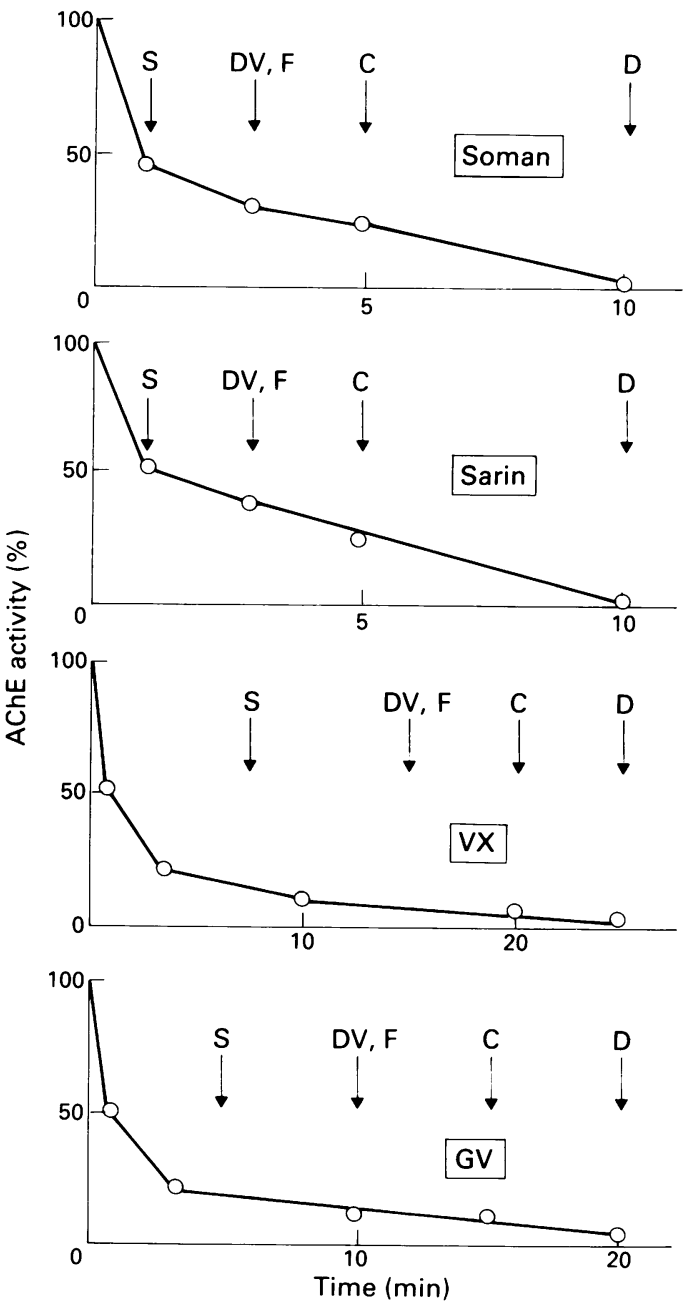

Figure 4 AChE activity changes in rat blood and occurrence of symptoms of poisoning after intoxication with the agents examined. The results are presented means only. $S=$ salivation; $D V, F=$ disturbed ventilation and fasciculations; $C=$ convulsions; $D=$ death.

muscular administration of soman, sarin, and VX. The doses were roughly $2 \times \mathrm{LD}_{50}$-namely, 0.36 $\mathrm{mg} / \mathrm{kg}$ for sarin, $0.154 \mathrm{mg} / \mathrm{kg}$ for soman, and 0.030 $\mathrm{mg} / \mathrm{kg}$ for VX.

INHIBITION OF AChE ACTIVITY IN VIVO BY GV For compound GV, female Wistar rats (Velaz Praha, Czechoslovakia) weighing 200-220 g were used. The animals were divided into groups of six animals. After intoxication with $\mathrm{GV}$ in a dose roughly $2 \times \mathrm{LD}_{50}(0.034 \mathrm{mg} / \mathrm{kg}), \mathrm{AChE}$ activity in the blood, regions of brain, and diaphragm was determined according to the method of Ellman et al. ${ }^{21}$
REACTIVATION OF AChE ACTIVITY IN VIVO

Reactivation of blood AChE activity in vivo was described previously. ${ }^{22}$ The method is based on a duplicate determination of AChE activity with and without reactivator (trimedoxime chloride, Léčiva Praha, Czechoslovakia) at a concentration with negligible effect $\left(5 \times 10^{-3} \mathrm{M}\right)$ on the hydrolysis of substrate, acetylthiocholine (Lachema Brno, Czechoslovakia). ${ }^{23}$ These experiments were performed on beagle dogs (Velaz Praha, Czechoslovakia) of both sexes, weighing 8-12 $\mathrm{kg},(\mathrm{n}=3-5)$. The dogs were anaesthetised and intoxicated by intramuscular injection of soman $(0.007 \mathrm{mg} / \mathrm{kg})$, sarin $(0.03 \mathrm{mg} / \mathrm{kg}), \mathrm{VX}(0.003 \mathrm{mg} / \mathrm{kg})$, or $\mathrm{GV}(0.004$ $\mathrm{mg} / \mathrm{kg}$ ). Blood was collected at different time intervals and the percentage of $\mathrm{AChE}$ activity or its reactivation was determined. In this case, the symptoms registered were only salivation and fasciculation. Convulsions and death were not seen because of the low doses of the agents used and modification of the symptoms by narcotisation.

\section{STATISTICAL EVALUATION AND CHEMICALS}

Statistical evaluation was performed with relevant programmes using a Turbo 12 computer. 5,5Dithiobis-2-nitrobenzoic acid (Serva Heidelberg, Germany) was used as chromogen for AChE activity determination. Other chemicals of analytical grade were obtained from Lachema Brno.

\section{Results}

Figure 4 shows the changes in $\mathrm{AChE}$ activities in rat blood. The decrease in half lives for activity of AChE in the materials examined (table) showed that, after soman intoxication, inhibition of $\mathrm{AChE}$ in the pontomedullar area and diaphragm proceeded quickly

Table Half lives of inhibition of AChE activity in vivo after sarin, soman, $V X$, or $G V$ poisoning

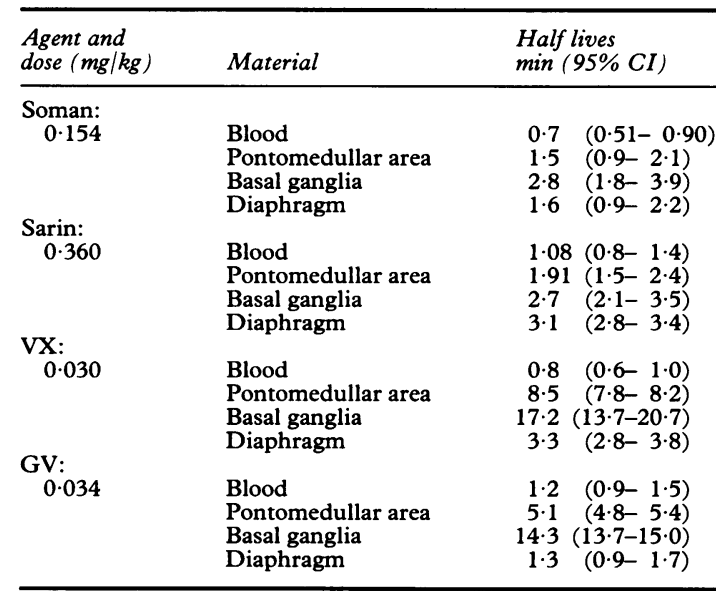




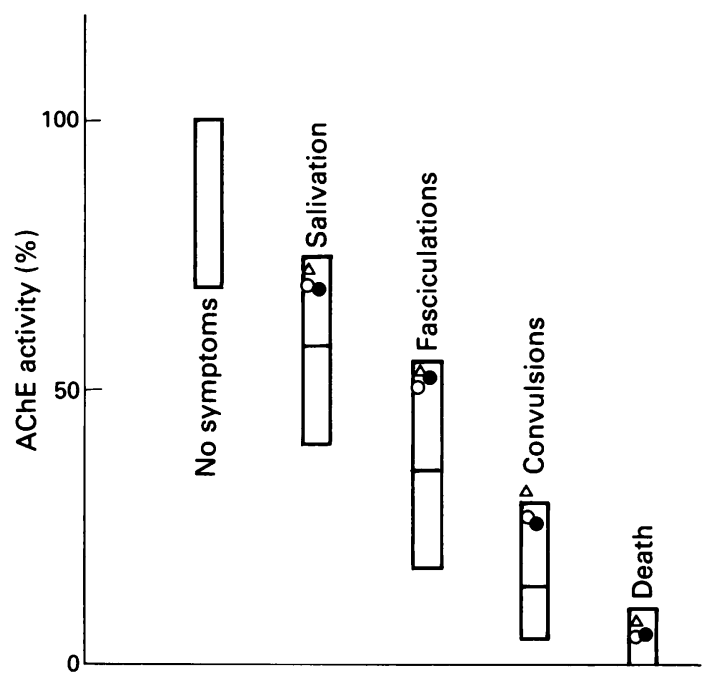

Figure 5 The range of $A C h E$ activity in rat blood corresponding to different symptoms of poisoning (mean values and $S D$ ). The points represent the mean values of blood AChE activity in rats exposed to organophosphorus insecticides according to published data. ${ }^{24-26}$

$\Delta$ = Trichlorfon; $\mathrm{O}=$ demeton;

$\widehat{0}=$ dichlorvos

and corresponded to that found in the blood. In sarin poisoning, the fastest rate and the greatest degree of $\mathrm{AChE}$ inhibition in the pontomedullar area, corresponding to that in the blood was seen. On the other hand, after VX or GV intoxication, the half lives of AChE inhibition were similar in the blood and diaphragm (table). If we summarise the results from different sources on rats, similar relations between enzyme inhibition and clinical state are obtained: near normal activity (70-100\%) corresponds to intoxication without symptoms. Salivation is seen when the activity is decreased to $60-70 \%$, fasciculations and dyspnoea are found if the $\mathrm{AChE}$ activity is below $55 \%$. When convulsions occurred, AChE activity was $15-30 \%$ and in the case of death, a maximum of $10 \%$ normal $\mathrm{AChE}$ activity was detected. These results were confirmed not only in experiments with the nerve agents but also in cases of intoxication with organophosphate insecticides like trichlorfon, ${ }^{24}$ demeton, ${ }^{25}$ and dichlorvos ${ }^{26}$ (fig 5).

After intoxication of the dogs with soman, a rapid decrease in blood AChE activity was recorded (fig 6). It reached a steady state 10 minutes after the injection of soman. The reactivation potential of blood AChE activity decreased with time and after 100 minutes AChE could not be reactivated at all (fig 6). A mean reactivation in the range of $0-16 \%$ was found.

In the case of sarin, a similar decrease in AChE activity was found (fig 6 ). On the other hand, reactiva- tion 100 minutes after the injection of sarin was seen: the mean reactivation for AChE activity inhibited by soman was about $60 \%$ (fig 6).

Prolonged inhibition of AChE activity was seen after VX intoxication, the steady state being achieved 50-60 minutes after the injection (fig 7). On the other hand, practically $100 \%$ reactivation in vivo was obtained 120 minutes after the intoxication (fig 7).

The course of AChE inhibition after GV intoxication was similar to that after VX (fig 7): the steady state occurred 60 minutes after the injection. The reactivation pattern of inhibited AChE activity, however, was different: it was similar to that found for soman, with less than $10 \%$ reactivation 60 minutes after intoxication (fig 7).

\section{Discussion}

From the results presented, a relation exists between signs of poisoning and changes in AChE activity in the blood for highly toxic organophosphates. These changes are similar to those seen in the target organs. The sites of the toxic effect are different for the different compounds studied. In the case of Gcompounds (sarin and soman), the activity of $\mathrm{AChE}$ in the brain is a better marker for poisoning than the enzyme activity in peripheral nervous tissues. Soman has a more uniform action than sarin. In the case of VX and GV, their effect on peripheral $\mathrm{AChE}$ activity was more pronounced and changes in AChE activity in the blood were similar to those in the diaphragm. This agrees with other results ${ }^{27}$ in which the inhibi-

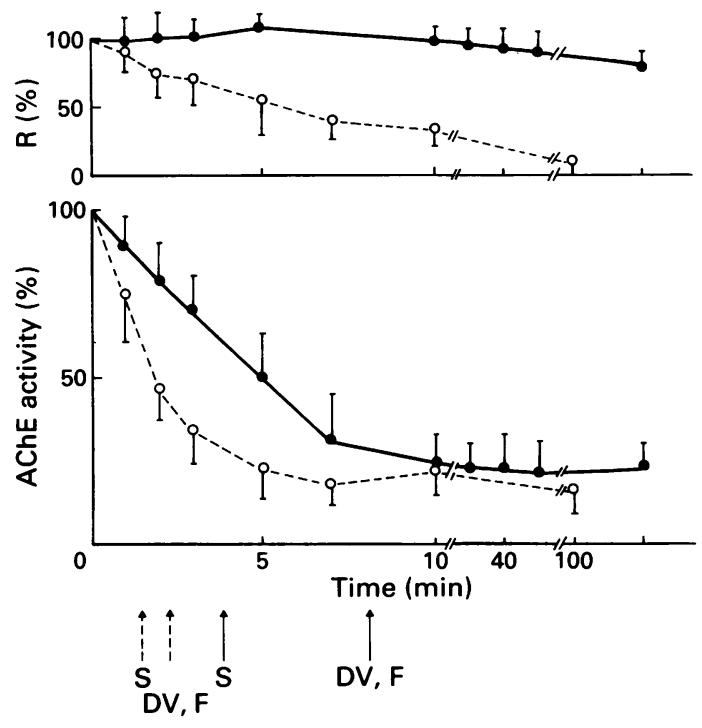

Figure 6 Changes in AChE activity (bottom) and its reactivation $(R)$ (top) in blood of dogs intoxicated with soman (O) and sarin (O). Results are means with $S D$. 

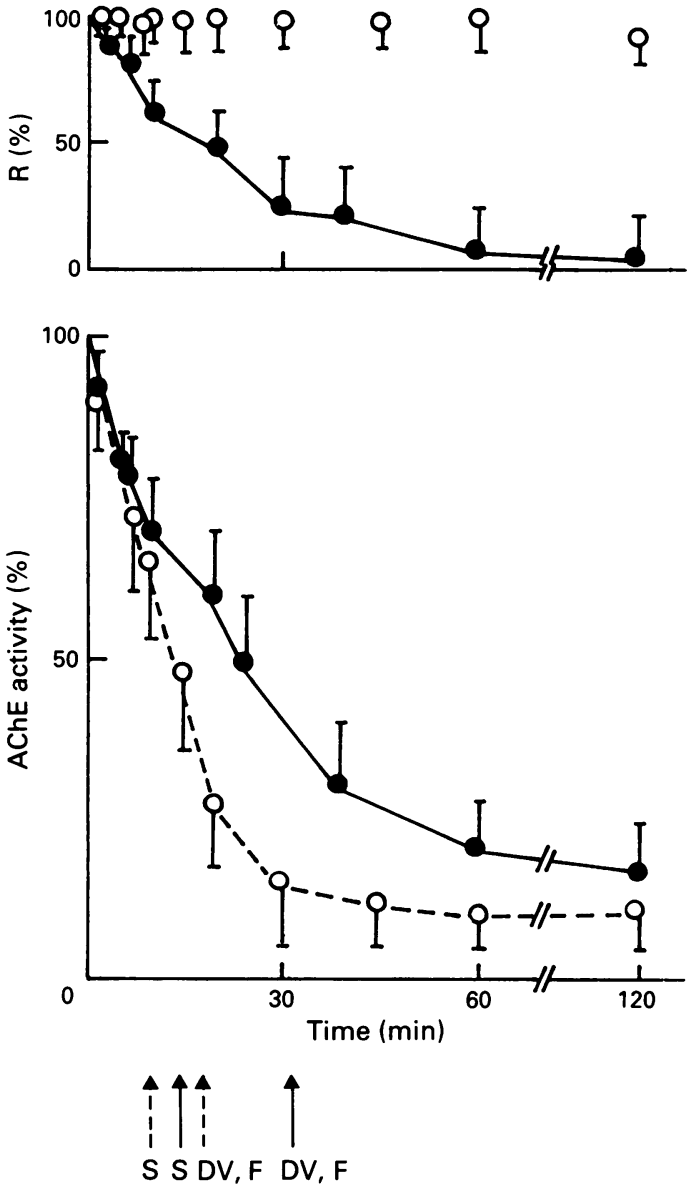

Figure 7 Changes in AChE activity (bottom) and its reactivation (top) in blood of dogs intoxicated with $V X(O$ and $G V(\bigcirc)$. Results are means with $S D$.

tion of cholinesterase activity in plasma or red blood cells occurred early in the clinical profile and is an especially important indicator of moderate exposure.

The results dealing with inhibition of $\mathrm{AChE}$ activity in blood and reactivation in dogs enable an assessment of half life periods for aging. For soman, it is a matter of minutes: for sarin it is more than two hours. Aging of AChE after VX administration was not seen within 24 hours. By contrast, for $G V$ a fast aging with a half life of 10 minutes was found. This is in agreement with published data for soman and sarin. ${ }^{14}{ }^{20}$ It is known from another study that aging rates of AChE activity inhibited by soman in vitro and in vivo are similar: the half life of erythrocyte $\mathrm{AChE}$ activity in the rat was 8.6 minutes, ${ }^{28}$ which compares favourably with our results on dogs.

It can be concluded that AChE activity in the blood is an appropriate parameter for biological monitoring of exposure to nerve gas. It does not allow an assessment of the extent of intoxication, however, or the prognosis of the repeated administration of reactivators. The test used in our experiments improves the prediction of further prognosis and enables a more rational treatment. Moreover, these results give some pointers as to the likely agent used. Where there is little or no reactivation (up to 10$20 \%$ ), the poisoning is probably caused by soman or GV: moderate reactivation (more than $50 \%$ ), would tend to indicate sarin intoxication. An $\mathrm{AChE}$ activity reactivated to $80 \%$ or more suggests that the toxic agent might be VX. These findings have obvious importance for cases of intoxication with organophosphorus insecticides; in most cases aging of AChE activity did not occur. Thus in instances of decreased AChE activity for reasons other than inhibition by organophosphorus insecticides (carbamates, metabolic or genetic diminution of activity etc) no reactivation will be found. ${ }^{22}{ }^{29} \mathrm{We}$ can assume that these two methods could serve as basic tests in the diagnosis of organophosphate poisoning.

I am indebted to Dr G Cooper of the British disarmament delegation in Geneva for his comments and suggestions, and I also thank Mrs M Zechovská, E Vodáková and J Petrová for skilled technical assistance and Mrs $\mathrm{H}$ Roobová for preparation of the manuscript.

1 Koelle GB. Cholinesterases and anticholinesterase agents. Handbuch der experimentellen Pharmakologie. Berlin: Springer-Verlag, 1963.

$2 \mathrm{CD} / 1108$. Document of conference on disarmament. Geneva, 1991.

3 Bruin de A. Anticholinesterase action-organophosphates and carbamates. In: Biochemical toxicology of environmental agents. Amsterdam: North Holland Biomedical Press, 1976: 981-1031.

4 Bajgar J. The role of cholinergic and non-cholinergic mechanisms following toxic effect of nerve agents. Voj zdrav Listy 1985a;54:24-9. (In Czech.)

5 Maxwell DM, Lenz DE, Groff WA, Kaminskis A, Froehlich HL. The effects of blood flow and detoxification on in vivo cholinesterase inhibition by soman in rats. Toxicol Appl Pharmacol 1987;88:66-76.

6 Maxwell DA, Vlahacos CP, Lenz DE. A pharmacodynamic model for soman in the rat. Toxicol Lett 1988;43:175-88.

7 Broomfield CA, Little JS, Lenz DE, Ray R. Organophosphorus acid anhydride hydrolases that lack chiral specificity. In: Reiner R, Aldridge WN, Hoskin FCG, eds. Enzymes hydrolysing organophosphorus compounds. New York: J Wiley and Sons, 1989:79-89.

8 Clement JG. Survivors of soman poisoning: recovery of the soman $\mathrm{LD}_{50}$ to control value in the presence of extensive acetylcholinesterase inhibition. Arch Toxicol 1989;63:150-4.

9 Jokanovic $M$. Role of carboxylesterase in soman, sarin and tabun poisoning in rats. Pharmacol Toxicol 1989;65:181-4.

10 Silver A. The biology of cholinesterases. In: Neuberger A, Tatum EL, eds. Frontiers in biology. Vol 36. Amsterdam: North Holland, 1974.

11 Aldridge WN. Organophosphorus compounds and carbamates and their reactions with esterases. Br Med Bull 1969;25:236-9.

12 Aldridge WN, Reiner E. Enzyme inhibitors as substrates. Amsterdam: North Holland, 1973.

13 Sidell FR, Aghajanian GK, Groff WA. The reversal of anticholinergic intoxication in man with the cholinesterase inhibitor VX. Proc Soc Exp Biol Med 1973;144:725-30.

14 Fleisher JH, Harris LW. Dealkylation as a mechanism for ageing of cholinesterase after poisoning with pinacolyl methylphosphonofluoridate. Biochem Pharmacol 1965;14:641-50. 
15 Bajgar J. Toxic effect of VX compound. Sbornik Voj Zdrav Listy 1978;1:30-40. (In Czech.)

16 Patočka J. Reactivation of isopropylmethylphosphonylated rat brain acetylcholinesterase by oximes. Coll Czech Chem Commun 1972;37:899-906.

17 Bajgar J, Jakl A. Inhibition of acetylcholinesterase in the rat blood and brain by pinacolyl methylphosphonofluoridate. $V o j$ Zdrav Listy 1970;39:253-5. (In Czech.)

18 Bajgar J. Inhibition of acetylcholinesterase in different parts of the rat brain by isopropyl methylphosphonofluoridate. In vitro and in vivo experiments. Biochem Pharmacol 1972a;21: 687-94.

19 Bajgar J. Time course of acetylcholinesterase inhibition in the medulla oblongata of the rat by O-ethyl S-(2-dimethylaminoethyl) methylphosphonothioate in vivo. BrJ Pharmacol 1972b;45:368-71.

20 Bajgar J. The influence of inhibitors and other factors on cholinesterases. Sbornik Vèd Praci LF UK v Hradci Králové 1991;34:3-75.

21 Ellman GL, Courtney KD, Andres V, Featherstone RM. A new and rapid colorimetric determination of acetylcholinesterase activity. Biochem Pharmacol 1961;7:88-95.

22 Bajgar J, Patočka J. Determination of cholinesterase activity by developing test Bio-La. Biochem Clin Bohemoslov 1985;14: 157-66. (In Czech.)

23 Patočka J, Baigar J, Bielavský J. Kinetics of hydrolysis of acetylthiocholine by oximes. Coll Czech Chem Commun 1973; 38:3685-93.

24 Bajgar J. Inhibition of molecular forms of cholinesterases in experimental Neguvon poisoning. Prac Lék 1985b;37:119-22. (In Czech.)

25 Baigar J. Activity changes of some tissue hydrolases of the rat following systox poisoning. Sbornik Věd Praci VLVDÚ Hradec Králové 1968;36:155-65.

26 Kassa J, Patočka J. Changes in cyclic nucleotides levels and cholinesterae activity in experimental poisonong of rats with Dichlorvos. Prac Lék 1989;41:204-8. (In Czech.)

27 Jimmerson VR, Shih TM, Mailman RB. Variability in soman toxicity in the rat: correlation with biochemical and behavioral measures. Toxicology 1989;57:241-54.

28 Talbot BG, Anderson DR, Harris LW, Zarbrourgh LW, Lennox WJ. A comparison of in vivo and in vitro rates of ageing of soman-inhibited erythrocyte acetylcholinesterase in different animals species. Drug Chem Toxicol 1988;11:289-305.

29 Bajgar J, Patočka J, Hrubecký J, Lacina P. Differentially diagnostic method for potvrzeni or excluding of organophosphorus insecticides intoxication. Acta Hyg Epid Microbiol App 1979;I:41-9. (In Czech.)

Accepted 18 November 1991 